\title{
STAP-2 Adaptor Protein Regulates Multiple Steps of Immune and Inflammatory Responses
}

\author{
Tadashi Matsuda $^{*, a}$ and Kenji Oritani ${ }^{b}$ \\ ${ }^{a}$ Department of Immunology, Graduate School of Pharmaceutical Sciences, Hokkaido University; \\ Kita 12, Nishi 6, Kita-ku, Sapporo 060-0812, Japan: and ${ }^{b}$ Department of Hematology, International \\ University of Health and Welfare; 4-3 Kouzunomori, Narita, Chiba 286-8686, Japan.
}

Received March 13, 2021; accepted April 20, 2021

\begin{abstract}
Signal-transducing adaptor protein (STAP)-2 is an adaptor molecule involved in regulation of several intracellular signaling events in immune cells. STAP-2 contains a pleckstrin homology domain at the N-terminus, an src homology domain in the central portion and a proline-rich region at the C-terminus. STAP-2 also has a YXXQ motif, which is a potential signal transducer and activator of transcription (STAT)3-binding site. STAP-2 influences the STAT3 and STAT5 activity, integrin-mediated $T$ cell adhesion, chemokineinduced $T$ cell migration, Fas-mediated $T$ cell apoptosis, Toll-like receptor-mediated macrophage functions, macrophage colony-stimulating factor-induced macrophage activation, and the high-affinity immunoglobulin $E$ receptor-mediated mast cell activation. This article reviews the current understanding of roles of the STAP-2 during immune and/or inflammatory responses, and discusses possible therapeutic applications of targeting STAP-2 proteins in immune-related disorders.
\end{abstract}

Key words signal-transducing adaptor protein (STAP)-2; adaptor protein; immune response; inflammation; signal transduction

\section{INTRODUCTION}

Adaptor proteins interact with a number of intracellular signaling molecules, resulting in the modification of their functions. ${ }^{1)}$ These adaptor proteins lack intrinsic catalytic activity, but have the ability to regulate signals by linking functional catalytic proteins. Adaptor proteins contain multiple proteininteracting modules, including the pleckstrin and/or src homology (SH) domains, which bring effector molecules and cellular enzymes into close proximity to their targets. In immune cells, some adaptor proteins have been shown to coordinate signaling pathways for their effector functions, such as cell migration, activation, proliferation, and differentiation. ${ }^{2)}$

Signal-transducing adaptor protein-2 (STAP-2) was first discovered as a c-Fms/macrophage colony-stimulating factor (M-CSF) receptor (M-CSFR)-interacting protein, and it has been subsequently found to act as an adaptor of signaling and transcription factors. ${ }^{3)}$ STAP-2 has high sequence and structural similarities to STAP-1, which has been cloned as a c-Kit-interacting protein. Both STAP-1 and STAP-2 contain a pleckstrin homology $(\mathrm{PH})$ domain $(36 \%$ identity and $58 \%$ similarity) in the $\mathrm{N}$-terminal region and a $\mathrm{SH} 2$ domain $(40 \%$ identity) in the central region ${ }^{3,4}$ (Fig. 1). STAP-2, but not STAP-1, has a proline-rich region and a YXXQ motif in the $\mathrm{C}$-terminal region. STAP-2 is abundantly expressed in various tissues and cells, ${ }^{3)}$ suggesting that STAP-2 has an ability to influence various cellular events (Fig. 2). Indeed, STAP-2 has been known to modulate the transcriptional activity of the signal transducer and activator of transcription (STAT) $3 / 5,{ }^{3,5-8}$ ) as well as high-affinity immunoglobulin $\mathrm{E}$ (IgE) receptor (FceRI)-, ${ }^{9,10)}$ M-CSFR-, ${ }^{11,12)}$ and Toll-like receptor (TLR)-mediated signals. ${ }^{13)}$ Moreover, our recent works have revealed the contribution of STAP-2 in integrin- ${ }^{14)}$ chemokine- ${ }^{15)}$ and Fasmediated signals. ${ }^{16)}$ In this review, we focus on the regulation of immune and inflammatory signaling by STAP-2.

\section{STAP-2 IN T CELLS}

$\mathrm{T}$ cells, a major component of the adaptive immune response, play an essential role in pathogen elimination. $\mathrm{T}$ cell receptor (TCR) ligation with an antigenic peptide presented on the major histocompatibility complex molecules of antigenpresenting cells initiates a variety of developmental and/or functional events. ${ }^{17)}$ These events include the selection, differentiation, and proliferation of $\mathrm{T}$ cells, and resulting cytokine production from $\mathrm{T}$ cells, and are optimally arranged to provide appropriate responses against a variety of pathogens that the host may encounter.

2.1. Effects of STAP-2 on T Cell Adhesion Cell adhesion, or the formation of conjugates of $\mathrm{T}$ cells with other immune cells, is an essential early step in immune responses.
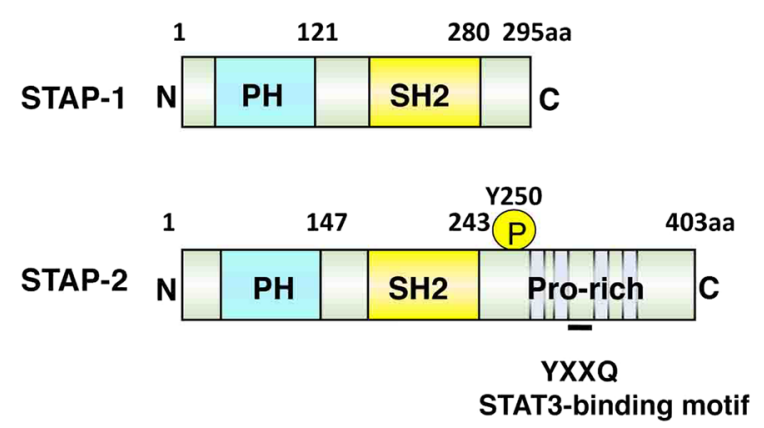

Fig. 1. Structural Features of STAP-1 and STAP-2

Both contain an amino $(\mathrm{N})$ terminal pleckstrin homology $(\mathrm{PH})$ domain, a central SRC homology 2 (SH2) domain, and STAP-2 has an additional carboxy (C)-terminal proline-rich domain. STAP-2 is phosphorylated at Tyr 250 (Y250) by a variety of protein tyrosine kinases. The YXXQ motif is involved in the STAT3-mediated signaling. aa: amino acid. (Color figure can be accessed in the online version.) 


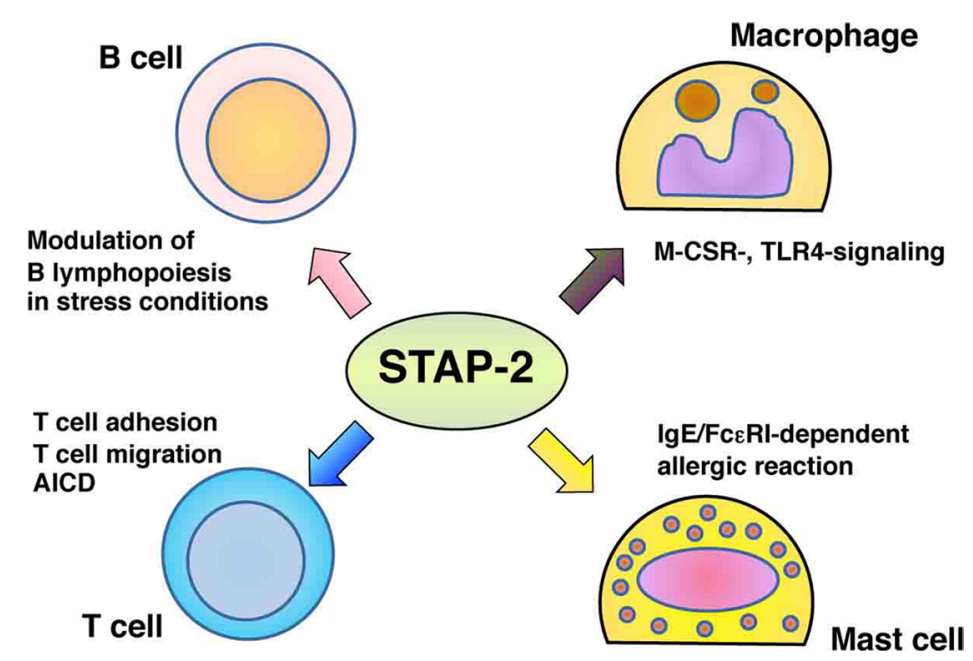

Fig. 2. STAP-2 Functions in Various Immune Signaling Pathways in Several Cell Types

M-CSF: macrophage-colony stimulating factor; TLR4: Toll-like receptor 4; AICD: activation-induced cell death; Fc\&RI: Fc epsilon receptor I. (Color figure can be accessed in the online version.)

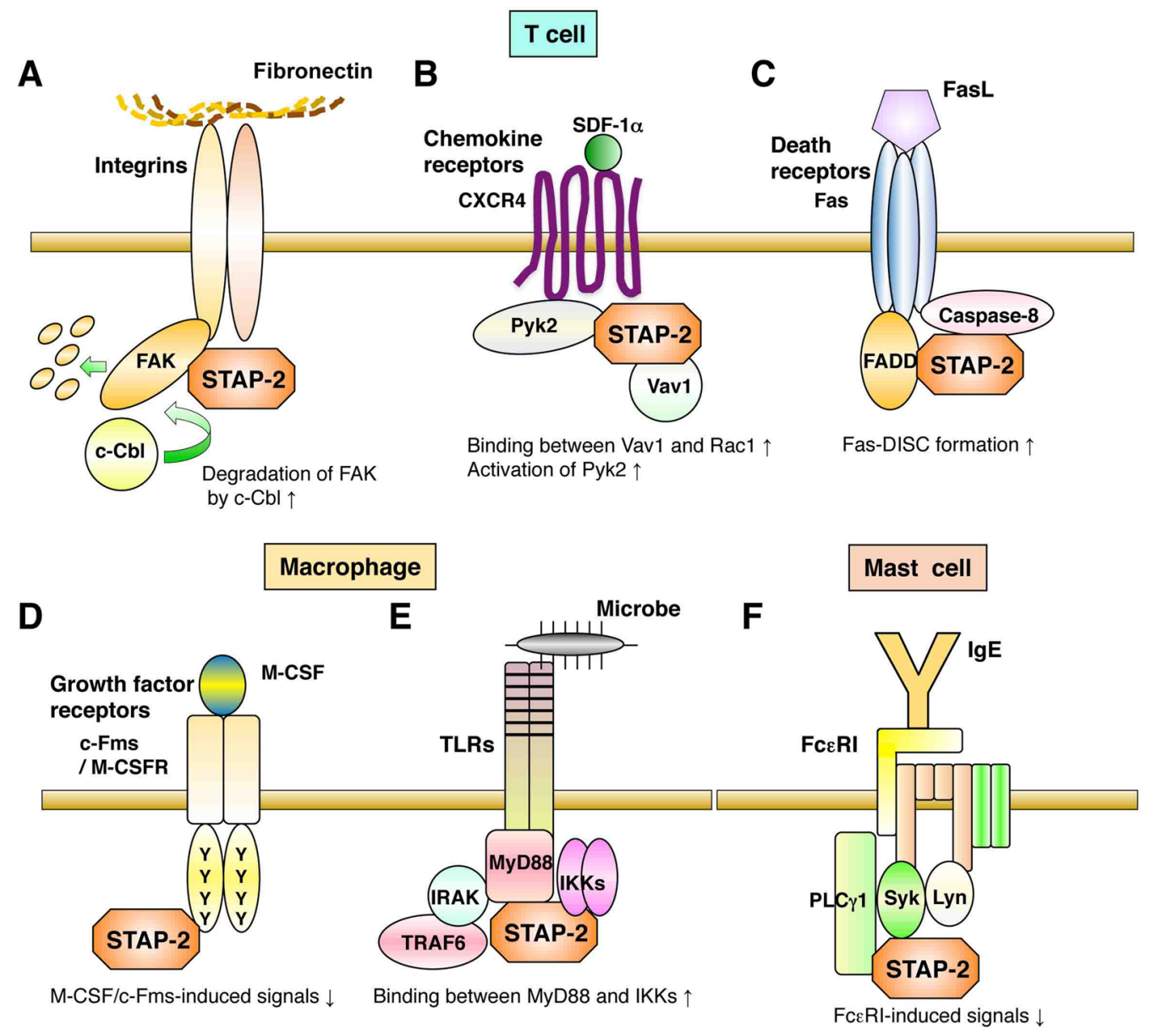

Fig. 3. STAP-2 Regulates a Variety of Immune Signaling Pathways through Interaction with Several Signaling Molecules

A-C, In T cells, STAP-2 can modulate the integrin-, Fas-, or SDF-1 $\alpha$-mediated signals. D, E, In macrophages, STAP-2 can modulate the M-CSF receptor (M-CSFR)- or Toll-like receptor 4 (TLR4)-mediated signals. F, In mast cells, STAP-2 can modulate the IgE/Fc\&RI-mediated signals. Through these interactions, STAP-2 plays physiological roles in immune responses. (Color figure can be accessed in the online version.)

Although the antigen-specific TCR confers antigen recognition and specificity, several cell surface molecules on $\mathrm{T}$ cells are involved in the regulation of lymphocyte migration and adhesion. $^{18,19)}$ One of the types of adhesion molecules that strengthen the binding of $\mathrm{T}$ cells are integrins and their li- gands, such as fibronectin (FN). The genetic ablation of focal adhesion kinase (FAK) resulted in early embryonic lethality in mice, and cells derived from these knockout embryos demonstrated severe migration and survival defects. ${ }^{20)}$ Conversely, overexpression of FAK increases cell motility and promotes 
cell survival in an anchorage-independent manner. ${ }^{21,22)}$ In general, the catalytic activation of FAK is triggered by the ligand binding of integrins, as well as autophosphorylation at Tyr397 that serves as a recognition site for Src family kinases. In addition, the SH2 domains also link FAK to the Grb2 adaptor protein, which then activates the Ras pathway. ${ }^{23)}$

STAP-2-deficient T cells exhibited high cell adhesion capacity to FN after phorbol myristate acetate treatment. ${ }^{14)}$ The STAP-2-deficient $\mathrm{T}$ cells contained elevated levels of FAK protein. Moreover, STAP-2 overexpression induced a dramatic decrease in the FAK protein level, and impaired integrinmediated adhesion to $\mathrm{FN}$ in Jurkat $\mathrm{T}$ cells. Regarding the molecular mechanisms, STAP-2 associates with FAK and enhances its degradation. STAP-2 recruits $\mathrm{c}-\mathrm{Cbl}$, an endogenous E3-ubiquitin ligase, to FAK (Fig. 3A). In addition, proteasome inhibitors significantly inhibit FAK degradation. STAP-2 colocalizes with FAK at focal-adhesion sites after the activation of integrins. Thus, STAP-2 is a regulatory molecule that can downregulate integrin-induced signaling in $\mathrm{T}$ cells, where STAP-2 negatively controls the FAK protein content via $\mathrm{c}-\mathrm{Cbl}$ -mediated protein degradation.

The central kinase domain of FAK protein provides the binding sites for many signaling molecules. ${ }^{19)}$ The N-terminal domain of FAK carries $\mathrm{F}$ for 4.1 protein, $\mathrm{E}$ for ezrin, $\mathrm{R}$ for radixin, and $\mathrm{M}$ for moesin (FERM) homology domain, and the C-terminal domain has two proline-rich regions and a focal adhesion targeting (FAT) domain. Notably, the N-terminal domain of FAK has the ability to bind to both STAP-2 and c-Cbl. These interactions may allow STAP-2 to recruit c-Cbl to FAK, thereby leading to enhanced FAK ubiquitination. This possibility was supported by studies telling that the FAK protein content in Jurkat/STAP-2 cells increases after the treatment with proteasome inhibitors; in addition, c-Cbl overexpression reduces and $\mathrm{c}-\mathrm{Cbl}$ knockdown increases the FAK protein content.

c-Cbl has a tyrosine kinase binding (TKB) domain and a RING finger domain at the N-terminus that forms the basic functional unit of a ubiquitin ligase. ${ }^{24,25)}$ The TKB domain recognizes a consensus phosphotyrosine motif, N/DXpYXXXf, where pY represents phosphorylated tyrosine residue and $\mathrm{f}$ represents a hydrophobic residue. ${ }^{26)}$ FAK becomes to be in active state with autophosphorylation at Tyr397 after integrin stimulation. The phosphorylated Tyr397 functions as a binding site for the $\mathrm{SH} 2$ domain of Src family kinases, followed by the subsequent phosphorylation of FAK at six tyrosine residues (Tyr397, Tyr407, Tyr576, Tyr577, Tyr861, and Tyr925). Among these tyrosine residues, the sequence surrounding Tyr397, DDYAEII, completely fits the consensus phosphotyrosine motif for the recognition by $\mathrm{c}-\mathrm{Cbl}$, thus indicating that $\mathrm{c}-\mathrm{Cbl}$ may recognize the sequence around the Tyr397 residue of FAK. c-Cbl negatively regulates integrin/FAK-mediated signals by promoting focal-adhesion disassembly. The STAP-2 protein level is likely to determine the focal-adhesion turnover, as well as the actin remodeling, by regulating the levels of FAK proteins.

STAP-2 may regulate a number of FAK-related cellular events, in addition to the integrin-induced adhesion of $\mathrm{T}$ cells to FN, because both FAK and STAP-2 are abundantly expressed in many types of cells and tissues. mRNA expression of STAP-2 was strongly induced by LIF stimulation in parallel with its differentiation into macrophages. ${ }^{3)}$ STAP-2 is also induced by lipopolysaccharide (LPS) or interleukin (IL)-6 stimulation in hepatocytes. The cell-type-restricted induction of STAP-2 may be beneficial to regulate the FAK protein content in specific cellular circumstances.

2.2. Effects of STAP-2 on T Cell Migration Chemokines, a group of chemoattractive cytokines, contribute to chemotaxis and transendothelial migration of leukocytes during immune and inflammatory reactions. ${ }^{19,27)}$ Stromal cell-derived factor (SDF)-1 $\alpha$ (also called CXCL12) is a member of the CXC chemokine family, which binds to the seven-transmembrane $\mathrm{G}$ protein-coupled receptors, CXCR4 and CXCR7. ${ }^{27)}$ The SDF-1 $\alpha /$ CXCR 4 interaction triggers many signaling events, including increased $\mathrm{Ca}^{2+}$ influx, extracellular signal-regulated kinase (ERK) phosphorylation, phosphatidylinositol 3-kinase (PI3K) activation, upregulation of nuclear factor-kappaB $(\mathrm{NF}-\kappa \mathrm{B})$ activity, and activation of the Rho family proteins, RhoA, Rac1, and Cdc42. ${ }^{28)}$ The SDF-1 $\alpha /$ CXCR4 interaction also induces chemotaxis through activating several signaling molecules, such as protein tyrosine kinase 2 (Pyk2). ${ }^{29)}$ SDF-1 $\alpha /$ CXCR4 plays an essential role in the homing of hematopoietic stem cells into bone marrow and the retention within an appropriate, supportive niche. In addition, the binding of SDF-1 $\alpha$ to CXCR4 induces an essential cell signaling system for immune cell trafficking and surveillance. Both SDF- $1 \alpha$ and CXCR4 knockout mice had significantly low numbers of lymphocytes and myeloid progenitors. ${ }^{30)}$ In addition to the movement of immune cells in vivo, SDF- $1 \alpha$ can induce the tight adhesion of rolling cells to endothelial cells, resulting in their subsequent transendothelial migration.

STAP-2 is a regulator of SDF- $1 \alpha$-induced chemotaxis of T cells. ${ }^{15)}$ STAP-2 expression enhanced, but a STAP-2 deficiency reduced, cell migration after SDF- $1 \alpha$-treatment in Jurkat $\mathrm{T}$ cells. Regarding the molecular mechanism, STAP-2 binds to Vav1, a guanine-nucleotide exchanging factor for Rac1, and enhances the downstream Vav1/Racl signaling ${ }^{31)}$ (Fig. 3B). The hematopoietic cell-specific protein, Vav1, catalyzes guanine nucleotide exchange in the Rho family proteins. ${ }^{31)}$ In this situation, STAP-2 constitutively interacts with both Vav1 and Racl and upregulates their binding. The other possible involvement of STAP-2 in SDF- $1 \alpha$-mediated signals is the regulation of Pyk2, which forms signaling complexes with paxillin, the CT10 regulator of kinase (Crk), and p130 Crkassociated substrate (Cas). ${ }^{32}$ STAP-2 directly interacts with Pyk2 and upregulates Pyk2 phosphorylation. Pyk2 itself can induce STAP-2 Tyr250 phosphorylation, which is critical for maximal interactions between STAP-2 and Pyk2 ${ }^{33)}$ (Fig. 3B). In addition, SDF- $1 \alpha$-induced T cell chemotaxis was inhibited by treatment with Pyk2 small interfering RNA (siRNA) or AG17, an inhibitor of Pyk2, in Jurkat $\mathrm{T}$ cells overexpressing STAP-2.

Therefore, STAP-2 is involved in chemokine-mediated lymphocyte trafficking and homing via regulating the functions of Rho proteins and Pyk2.

2.3. Effects of STAP-2 on Activation-Induced Cell Death (AICD) After the clearance of the antigens, the activated $\mathrm{T}$ cells should die to preclude the accumulation of no-longer-needed and potentially dangerous effector cells, and thereby prevents from occurring autoimmune diseases. This induction of apoptosis, termed AICD, is triggered by mitochondria apoptotic and/or Fas signaling pathways. ${ }^{34)}$ Fas oligomerization results in Fas-death-inducing signaling complex 
(Fas-DISC) formation that initiates apoptosis. In natural mutant mice with the Fas or FasL gene, severe lymphoproliferation occurs even in germ-free environments, and is frequently associated with autoimmunity. ${ }^{35)}$ Caspase- 8 activation occurs in the Fas-DISC. The recruitment of Fas-associated protein with death domain (FADD) to Fas initiates the dimerization and conformational changes of caspase- 8 , leading to the full enzymatic activity of caspase- 8 . Then, active caspase- 8 undergoes autoproteolytic processing and leaves the Fas-DISC to access its substrates.

STAP-2 acts as a new member of the Fas-DISC and participates in AICD. ${ }^{16}$ ) STAP-2 expression upregulates Fasmediated apoptosis and caspase- 8 aggregation/activation in Jurkat T cells. STAP-2 directly interacts with caspase- 8 and Fas, leading to enhanced caspase- 8 and FADD interactions in the Fas-DISC. Similar to FLICE (Expression of Fas-associated death domain-like interleukin (IL)- $1 \beta$-converting enzyme)associated huge (FLASH), STAP-2 recognizes caspase- 8 death effector domain (DED), even under steady-state conditions, and enhances the interaction between FADD and caspase-8, as well as the activation and aggregation of caspase- 8 during Fas signaling (Fig. 3C). In addition, the STAP-2C-terminal domain has a consensus caspase- 8 cleavage sequence, VEAD, and the processing of STAP- 2 protein by caspase- 8 is crucial for Fas-induced apoptosis. The physiological roles of STAP-2 expression have been confirmed by observations that STAP2-deficient mice displayed impaired AICD and superantigeninduced $\mathrm{T}$ cell depletion.

Therefore, STAP-2 is a regulator of Fas signals that induces $\mathrm{T}$ cell apoptosis during AICD.

\section{STAP-2 IN MACROPHAGES}

During the inflammatory process, macrophages play central roles in producing inflammatory cytokines, such as IL-1, IL-6, and tumor necrosis factor (TNF)- $\alpha$ that initiate and spread inflammation to eliminate foreign pathogens. The TLR4 on macrophages recognizes pathogen-associated molecular patterns, such as LPSs, and mediates signals for cytokine production. $^{36)}$

3.1. Effects of STAP-2 on M-CSF/c-Fms Signaling $\mathrm{M}-\mathrm{CSF}$ induces the dimerization of its receptor c-Fms, leading to the autophosphorylation of tyrosine residues in the cytoplasmic domain that serve as binding sites for SH2-containing proteins, such as Src-family kinases, Grb2, and PI3K. ${ }^{37)}$ These proteins then facilitate the activation of signaling pathways that control the proliferation, differentiation, and motility in macrophages. In addition, the activation of extracellular signal-regulated kinases promotes macrophage proliferation, while PI3K activation enhances macrophage survival and migration.

STAP-2 was originally identified as a c-Fms/M-CSF receptor binding partner. ${ }^{3)}$ STAP-2 overexpression in a macrophage cell line, Raw264.7, downregulates M-CSF-induced tyrosine phosphorylation of c-Fms and downstream signaling proteins, such as PI3K/Akt and Ras/ERK. ${ }^{11)}$ Notably, c-Fms directly interacts with the STAP-2 PH domain. Ectopically expressed STAP-2 downregulates M-CSF-induced migration and woundhealing processes. Bone marrow-derived macrophages from STAP-2 deficient mice exhibited enhanced M-CSF-induced signals and an efficient wound-healing process. ${ }^{12)}$ Endogenous
STAP-2 also regulates M-CSF-induced signaling events, such as the activation of PI3K/Akt and Ras/ERK. Taken together with the fact that STAP-2 deficiency results in an increase in the macrophage migration capacity, STAP-2 appears to act as an endogenous regulator of normal macrophage functions (Fig. 3D).

The c-Fms-mediated signaling pathway must be tightly regulated to maintain macrophage homeostasis. SOCS-1 and Dok-2 are the main proteins that negatively regulate c-Fms signaling. ${ }^{38,39)}$ SOCS-1 partially suppresses M-CSF signaling by competing with Grb2, phospholipase C- $\gamma 2$, or PI3K for the binding to Tyr697 and/or Tyr721 in the activated c-Fms. Dok-2 regulates c-Fms signaling via the inhibition of Shc phosphorylation by Src-family kinases, leading to the insufficient inducible gene expression. Another key protein involved in the negative regulation is $\mathrm{c}-\mathrm{Cbl}$, a ubiquitin ligase. ${ }^{40)} \mathrm{c}-\mathrm{Cbl}$ terminates c-Fms signaling through the association with the phosphorylated Tyr973 of c-Fms and through the recruitment of E2-ubiquitin ligases to the receptor. Subsequent c-Fms polyubiquitination by $\mathrm{c}-\mathrm{Cbl}$ targets $\mathrm{c}-\mathrm{Fms}$ for internalization and degradation. Notably, it is possible that STAP-2 also participates in the c-Cbl-mediated regulation of c-Fms signaling because c-Cbl can bind to STAP-2. ${ }^{41)}$ Thus, STAP-2 has direct and/or indirect regulatory effects on c-Fms-mediated signals.

The possible involvement of STAP-2 in M-CSF/c-Fmsinduced signals is likely to provide new insights to understand the molecular mechanisms of macrophage homeostasis, and suggests the possibility that STAP-2 may be a novel therapeutic drug candidate to modulate inflammation and/or the wound-healing process.

3.2. Effects of STAP-2 on LPS/TLR4 Signaling TLR family proteins are characterized by the presence of leucinerich repeats in the extracellular domains and Toll/IL-1 receptor homology domains in the intracytoplasmic regions. ${ }^{36}$ ) These proteins are widely expressed on a variety of cells, such as macrophages and dendritic cells, and serve an essential link between the innate and adaptive immune responses. TLRs recognize specific microbial pathogen-associated molecular patterns to evoke inflammatory responses. Ligand ligation of TLRs induces signals to activate NF- $\kappa \mathrm{B}$ and mitogen-activated protein kinases, followed by the expression of costimulatory molecules and the production of inflammatory cytokines. Subsequently, the secreted inflammatory cytokines activate macrophages and natural killer cells that directly kill pathogens as well as enhance clonal $\mathrm{B}$ and $\mathrm{T}$ cell responses.

STAP-2 positively regulates LPS/TLR4-induced signals in macrophages. ${ }^{13)}$ Disruption of STAP-2 reduces, and overexpression of STAP-2 enhances, LPS/TLR4-induced NF- $\kappa$ B activation and cytokine production. The SH2 domain of STAP-2 binds to both MyD88 and inhibitor of nuclear factor-kappa B (I $\kappa \mathrm{B})$ kinase (IKK)- $\alpha / \beta$, but not TNF receptor-associated factor 6 (TRAF6) or IL-1 receptor associated kinase 1 (IRAK1), and forms a functional complex composed of MyD88, STAP-2, and IKK- $\alpha / \beta$ (Fig. 3E). These interactions enhance MyD88- and/or IKK- $\alpha / \beta$-dependent signals, resulted in the elevation of NF- $\kappa \mathrm{B}$ activity. Macrophages express STAP-2 constitutively. In addition, the $5^{\prime}$ region of the STAP-2 genomic sequence contains several potential binding sites for c-Rel, AP-1, p65/NF- $\kappa$ B, and STAT proteins. ${ }^{3)}$ In a murine myeloid leukemia cell line M1, upon LIF stimulation, STAP-2 mRNA expression is strongly induced in parallel with its differen- 
tiation into macrophages. This expression pattern of STAP-2 strengthens the possibility that STAP-2 in macrophages may regulate signals for acute-phase responses after infection. Indeed, STAP-2 expression upregulated TNF- $\alpha$ production at an early stage after LPS exposure in vivo.

The activation of the classical NF- $\kappa \mathrm{B}$ pathway converges on the IKK signalosome, a protein complex composed of IKK- $\alpha$ and IKK- $\beta$ subunits and the non-catalytic subunit $\mathrm{NF}-\kappa \mathrm{B}$ essential modulator. ${ }^{42)}$ Activated IKK phosphorylates $\mathrm{I} \kappa \mathrm{B}$ proteins, which sequester $\mathrm{NF}-\kappa \mathrm{B}$ in the cytoplasm. The main pathway to activate NF- $\kappa \mathrm{B}$ after the ligand ligation of TLR4 in macrophages is by MyD88-IRAK1-TRAF6-IKKmediated phosphorylation of $\mathrm{I} \kappa \mathrm{B}$ as well as TRAF6-mediated c-Jun N-terminal kinase (JNK) and p38 mitogen-activated protein kinase (MAPK) activation. A possible alternative signaling pathway with a direct link between MyD88 and the IKK complex may be mediated by STAP-2. This possible idea has been established from our following data: (i) STAP-2 binds to MyD88 and IKK- $\alpha / \beta$, but not IRAK1 or TRAF6; (ii) the association between MyD88 and IKK- $\beta$ is detected only when STAP-2 is present; (iii) STAP-2 enhances MyD88- and IKK- $\alpha / \beta$-induced NF- $\kappa \mathrm{B}$ activity; and (iv) STAP-2 enhances the kinase activity of IKK- $\beta$.

Therefore, STAP-2 acts as an adaptor protein that acts as a linker between MyD88 and IKK- $\alpha / \beta$ in TLR4 signaling. The proposed signaling pathway involving STAP-2 will provide new insights to understand the molecular mechanisms of TLR4-downstream signals. In addition, STAP-2 could be considered as a suitable candidate for an anti-inflammatory drug to regulate the NF- $\kappa \mathrm{B}$ activity.

\section{STAP-2 IN MAST CELLS}

Type I hypersensitivity reactions cause allergic skin inflammation and allergic asthma as well as food and drug allergies, and can sometimes lead to life-threatening anaphylaxis. ${ }^{43}$ Mast cells play a central role in IgE-dependent allergic diseases. ${ }^{43,44)}$ These cells constitutively express Fc $\varepsilon$ RI on their surfaces. Aggregation of FceRI eventually results in the release of granule components, such as histamine, and alteration of the adhesive property, cell shape, and surface topography of cells, as well as the de novo synthesis of lipid mediators and cytokines. ${ }^{45)}$ Several molecules are known to be crucial for the earliest activation steps in the FceRI-induced signals. ${ }^{44)}$ For example, Lyn binds to FceRI, and initiates its downstream signaling cascades. Syk is essential for the phosphorylation of several substrates, such as phospholipase C- $\gamma 1$ isoform (PLC- $\gamma 1){ }^{45,46)}$ PLC- $\gamma 1$ catalyzes the hydrolysis of phospholipids with the formation of diacylglycerol and inositol 1,4,5-triphosphate that is required for calcium mobilization. ${ }^{45}$ ) These activation signals are subsequently inhibited by negative signals, which allow mast cells to return to the basal resting condition. Thus, the downstream signals underlying FceRI are highly ordered, sequential molecular events. ${ }^{44)}$ Upon FceRI stimulation, IKK- $\beta$ in mast cells is known to be recruited into lipid raft fractions and to phosphorylate SNAP-23. ${ }^{47)}$ This IKK- $\beta$-mediated pathway also leads to the induction of degranulation.

STAP-2 is a substrate for Syk ${ }^{9)}$ and STAP-2 also interacts with PLC- $\gamma 1$ and IKK- $\beta .^{9,13)}$ STAP-2 can also physically bind to $\mathrm{Fc} \varepsilon \mathrm{RI}^{10)}$ (Fig. 3F). Thus, STAP-2 is likely to modify Fe $\varepsilon$ RI- induced signals at multiple steps. Indeed, STAP-2 overexpression in the rat basophilic leukemia cell line, RBL-2H3, results in a dramatic decrease in FceRI-mediated tyrosine phosphorylation of PLC- $\gamma 1$, calcium mobilization, and degranulation. In addition, Mast cells derived from STAP-2-deficient bone marrow shows highly elevated calcium entry, degranulation, and cytokine secretion, compared with wild-type mast cells, after FceRI stimulation, thus suggesting that STAP-2 may have a potential to negatively regulate FceRI-mediated signals. In in vivo experimental models, STAP-2-deficient mice challenged with dinitrophenyl (DNP)-BSA after passive sensitization with anti-DNP IgE show more severe decreases of rectal temperature than wild-type mice. STAP-2-deficient mice also displayed higher vascular permeability and more serious cutaneous anaphylaxis after DNP-BSA injection. Taken together with the fact that STAP-2 expression is constitutively observed in mast cells, STAP-2 is likely to be an intrinsic negative regulator of allergy.

Type I hypersensitivity reactions are often triggered by FceRI-induced signals in mast cells. Thus, the inhibiters of signals from FceRI are used in various therapeutic approaches for treating allergies. ${ }^{48,49)}$ For example, monoclonal antibodies specific for IgE are effective tools to treat patients with asthma and peanut allergies. ${ }^{48,49)}$ The inhibition of downstream signaling molecules, such as Syk, may also be a possible strategy for such treatments. The manipulation of STAP-2 expression or function in mast cells is also likely to control the pathogenesis of allergies and to have a potential to treat patients with allergic diseases.

\section{CONCLUSION}

In this review, we have summarized the influence of the STAP-2 adaptor protein on immune and inflammatory signaling. In T cells, STAP-2 directly interacts with and degrades FAK by recruiting an E3-ubiquitin ligase, c-Cbl, and altering the cell adhesion to $\mathrm{FN}^{14)}$ STAP-2 regulates SDF-1 $\alpha$-induced chemotaxis of $\mathrm{T}$ cells via the activation of Vavl/Racl signaling. ${ }^{15)}$ STAP-2 participates in AICD through direct interactions between caspase- 8 and Fas. ${ }^{16)}$ In macrophages, STAP-2 directly interacts with c-Fms, resulted in a high capacity for cell migration. ${ }^{11,12)}$ STAP-2 also functions to link MyD88 and IKK- $\alpha / \beta$, and upregulates LPS/TLR4 signaling. ${ }^{13)}$ In mast cells, STAP-2 functions as an intrinsic negative regulator of allergic responses. ${ }^{10)}$

The STAP-2 genomic sequence contains several potential binding sites for $\mathrm{c}-\mathrm{Rel}$, AP-1, p $65 / \mathrm{NF}-\kappa \mathrm{B}$, and STAT proteins within two $\mathrm{kb}$ of the $5^{\prime}$ flanking region of its transcription initiation site. ${ }^{3)}$ These transcription factors are often activated by bacterial pathogens and inflammatory cytokines. Indeed, STAP-2 expression is highly induced by several inflammatory cytokines, such as IL- 6 and TNF- $\alpha^{3)}$, while the expression of STAP-2 is ubiquitous under steady state conditions. Importantly, Stap-2 gene targeted and/or transgenic mice grew normally and did not exhibit any detrimental phenotypes in their immune systems under steady state conditions. However, several mouse models for immune/inflammatory diseases, such as inflammatory bowel diseases, ${ }^{50)}$ hematopoietic stem cell transplantation, ${ }^{51)}$ and graft-versus-host diseases, ${ }^{52)}$ clearly indicated that STAP-2 expression influenced the onset and development of these diseases. Therefore, detailed understanding 
of the molecular interactions between STAP-2 and its partner signaling molecules will provide useful information for the development of new drugs to control immune, inflammatory, and allergic disorders in the future.

Acknowledgments The authors thank Victoria Muir, Ph.D., edited a draft of this manuscript. This study was supported in part by Grant-in-Aid for scientific research 19H03364 (T.M.) from Ministry of Education, Culture, Sports, Science and Technology of Japan.

Conflict of Interest The authors declare no conflict of interest.

\section{REFERENCES}

1) Flynn DC. Adaptor proteins. Oncogene, 20, 6270-6272 (2001).

2) Jordan MS, Singer AL, Koretzky GA. Adaptors as central mediators of signal transduction in immune cells. Nat. Immunol., 4, $110-116$ (2003).

3) Minoguchi M, Minoguchi S, Aki D, Joo A, Yamamoto T, Yumioka T, Matsuda T, Yoshimura A. STAP-2/BKS, an adaptor/docking protein, modulates STAT3 activation in acute-phase response through its YXXQ motif. J. Biol. Chem., 278, 11182-11189 (2003).

4) Masuhara M, Nagao K, Nishikawa M, Sasaki M, Yoshimura A, Osawa M. Molecular cloning of murine STAP-1, the stem-cellspecific adaptor protein containing $\mathrm{PH}$ and $\mathrm{SH} 2$ domains. Biochem. Biophys. Res. Commun., 268, 697-703 (2000).

5) Ikeda O, Miyasaka Y, Sekine Y, Mizushima A, Muromoto R, Nanbo A, Yoshimura A, Matsuda T. STAP-2 is phosphorylated at tyrosine-250 by Brk and modulates Brk-mediated STAT3 activation. Biochem. Biophys. Res. Commun., 384, 71-75 (2009).

6) Ikeda O, Sekine Y, Mizushima A, Nakasuji M, Miyasaka Y, Yamamoto C, Muromoto R, Nanbo A, Oritani K, Yoshimura A, Matsuda T. Interactions of STAP-2 with Brk and STAT3 participate in cell growth of human breast cancer cells. J. Biol. Chem., 285, 3809338103 (2010).

7) Sekine Y, Yamamoto $T$, Yumioka T, Sugiyama K, Tsuji S, Oritani K, Shimoda K, Minoguchi M, Yoshimura A, Matsuda T. Physical and functional interactions between STAP-2/BKS and STAT5. $J$. Biol. Chem., 280, 8188-8196 (2005).

8) Ikeda O, Mizushima A, Sekine Y, Yamamoto C, Muromoto R Nanbo A, Oritani K, Yoshimura A, Matsuda T. Involvement of STAP-2 in Brk-mediated phosphorylation and activation of STAT5 in breast cancer cells. Cancer Sci., 102, 756-761 (2011).

9) Yamamoto T, Yumioka T, Sekine Y, Sato N, Minoguchi M, Yoshimura A, Matsuda T. Regulation of FcepsilonRI-mediated signaling by an adaptor protein STAP-2/BKS in rat basophilic leukemia RBL-2H3 cells. Biochem. Biophys. Res. Commun., 306, 767-773 (2003).

10) $\overline{\text { Sekine }} Y$, Nishida $K$, Yamasaki S, Muromoto R, Kon S, Kashiwakura J, Saitoh K, Togi S, Yoshimura A, Oritani K, Matsuda T. Signal-transducing adaptor protein-2 controls the IgE-mediated, mast cell-mediated anaphylactic responses. J. Immunol., 192, 34883495 (2014)

11) Ikeda O, Sekine Y, Kakisaka M, Tsuji S, Muromoto R, Ohbayashi N, Oritani K, Yoshimura A, Matsuda T. STAP-2 regulates cFms/M-CSF receptor signaling in murine macrophage Raw264.7 cells. Biochem. Biophys. Res. Commun., 358, 931-937 (2007).

12) Ikeda O, Sekine Y, Muromoto R, Ohbayashi N, Yoshimura A, Matsuda T. Enhanced c-Fms/M-CSF receptor signaling and woundhealing process in bone marrow-derived macrophages of signaltransducing adaptor protein-2 (STAP-2) deficient mice. Biol. Pharm. Bull., 31, 1790-1793 (2008).

13) Sekine Y, Yumioka T, Yamamoto T, Muromoto R, Imoto S, Sugi- yama K, Oritani K, Shimoda K, Minoguchi M, Akira S, Yoshimura A, Matsuda T. Modulation of TLR4 signaling by a novel adaptor protein signal-transducing adaptor protein-2 in macrophages. $\mathrm{J}$. Immunol., 176, 380-389 (2006).

14) Sekine Y, Tsuji S, Ikeda O, Sugiyma K, Oritani K, Shimoda K, Muromoto R, Ohbayashi N, Yoshimura A, Matsuda T. Signal-transducing adaptor protein-2 regulates integrin-mediated $\mathrm{T}$ cell adhesion through protein degradation of focal adhesion kinase. J. Immunol., 179, 2397-2407 (2007).

15) Sekine Y, Ikeda O, Tsuji S, Yamamoto C, Muromoto R, Nanbo A, Oritani K, Yoshimura A, Matsuda T. Signal-transducing adaptor protein-2 regulates stromal cell-derived factor-1 alpha-induced chemotaxis in T cells. J. Immunol., 183, 7966-7974 (2009).

16) Sekine Y, Yamamoto C, Kakisaka M, Muromoto R, Kon S, Ashitomi D, Fujita N, Yoshimura A, Oritani K, Matsuda T. Signal-transducing adaptor protein-2 modulates Fas-mediated $\mathrm{T}$ cell apoptosis by interacting with caspase-8. J. Immunol., 188, 6194-6204 (2012).

17) Gaud G, Lesourne R, Love PE. Regulatory mechanisms in T cell receptor signalling. Nat. Rev. Immunol., 18, 485-497 (2018).

18) Dustin ML, Bivona TG, Philips MR. Membranes as messengers in T cell adhesion signaling. Nat. Immunol., 5, 363-372 (2004).

19) Mora JR, von Andrian UH. T-cell homing specificity and plasticity: new concepts and future challenges. Trends Immunol., 27, 235-243 (2006).

20) Mitra SK, Hanson DA, Schlaepfer DD. Focal adhesion kinase: in command and control of cell motility. Nat. Rev. Mol. Cell Biol., 6 , 56-68 (2005)

21) Cary LA, Chang JF, Guan JL. Stimulation of cell migration by overexpression of focal adhesion kinase and its association with Src and Fyn. J. Cell Sci., 109, 1787-1794 (1996).

22) Frisch SM, Vuori K, Ruoslahti E, Chan-Hui PY. Control of adhesion-dependent cell survival by focal adhesion kinase. J. Cell Biol., 134, 793-799 (1996).

23) Schlaepfer DD, Hanks SK, Hunter T, van der Geer P. Integrin-mediated signal transduction linked to Ras pathway by GRB2 binding to focal adhesion kinase. Nature, 372, 786-791 (1994).

24) Duan L, Reddi AL, Ghosh A, Dimri M, Band H. The Cbl family and other ubiquitin ligases: destructive forces in control of antigen receptor signaling. Immunity, 21, 7-17 (2004).

25) Mueller DL. E3 ubiquitin ligases as T-cell anergy factors. Nat. Immunol., 5, 883-890 (2004).

26) $\mathrm{Hu}$ J, Hubbard SR. Structural characterization of a novel Cbl phosphotyrosine recognition motif in the APS family of adapter proteins. J. Biol. Chem., 280, 18943-18949 (2005).

27) Rossi D, Zlotnik A. The biology of chemokines and their receptors. Annu. Rev. Immunol., 18, 217-242 (2000).

28) Patrussi L, Baldari CT. Intracellular mediators of CXCR4-dependent signaling in T cells. Immunol. Lett., 115, 75-82 (2008).

29) Fernandis AZ, Prasad A, Band H, Klösel R, Ganju RK. Regulation of CXCR4-mediated chemotaxis and chemoinvasion of breast cancer cells. Oncogene, 23, 157-167 (2004).

30) Nagasawa T, Hirota S, Tachibana K, Takakura N, Nishikawa S, Kitamura Y, Yoshida N, Kikutani H, Kishimoto T. Defects of B-cell lymphopoiesis and bone-marrow myelopoiesis in mice lacking the CXC chemokine PBSF/SDF-1. Nature, 382, 635-638 (1996).

31) Bustelo XR. Regulatory and signaling properties of the Vav family. Mol. Cell. Biol., 20, 1461-1477 (2000).

32) Okabe S, Fukuda S, Kim YJ, Niki M, Pelus LM, Ohyashiki K, Pandolfi PP, Broxmeyer HE. Stromal cell-derived factor- $1 \alpha /$ CXCL12induced chemotaxis of $\mathrm{T}$ cells involves activation of the RasGAPassociated docking protein p62Dok-1. Blood, 105, 474-480 (2005).

33) Saitoh K, Tsuchiya T, Kashiwakura JI, Muromoto R, Kitai Y, Sekine Y, Oritani K, Matsuda T. STAP-2 interacts with Pyk2 and enhances Pyk2 activity in T-cells. Biochem. Biophys. Res. Commun., 488, 81-87 (2017).

34) Krammer PH, Arnold R, Lavrik IN. Life and death in peripheral $\mathrm{T}$ 
cells. Nat. Rev. Immunol., 7, 532-542 (2007).

35) Nagata S, Suda T. Fas and Fas ligand: lpr and gld mutations. Immunol. Today, 16, 39-43 (1995).

36) Akira S, Takeda K, Kaisho T. Toll-like receptors: critical proteins linking innate and acquired immunity. Nat. Immunol., 2, 675-680 (2001).

37) Sherr CJ, Rettenmier CW, Sacca R, Roussel MF, Look AT, Stanley ER. The c-fms proto-oncogene product is related to the receptor for the mononuclear phagocyte growth factor, CSF-1. Cell, 41, 665-676 (1985).

38) Suzu S, Tanaka-Douzono M, Nomaguchi K, Yamada M, Hayasawa H, Kimura F, Motoyoshi K. p56 (dok-2) as a cytokine-inducible inhibitor of cell proliferation and signal transduction. EMBO J., 19, 5114-5122 (2000).

39) Bourette RP, De Sepulveda P, Arnaud S, Dubreuil P, Rottapel R, Mouchiroud G. Suppressor of cytokine signaling 1 interacts with the macrophage colony-stimulating factor receptor and negatively regulates its proliferation signal. J. Biol. Chem., 276, 22133-22139 (2001).

40) Lee PS, Wang Y, Dominguez MG, Yeung YG, Murphy MA, Bowtell DD, Stanley ER. The Cbl protooncoprotein stimulates CSF-1 receptor multiubiquitination and endocytosis, and attenuates macrophage proliferation. EMBO J., 18, 3616-3628 (1999).

41) Sekine Y, Yamamoto C, Ikeda O, Muromoto R, Nanbo A, Oritani $\mathrm{K}$, Yoshimura A, Matsuda T. The protein content of an adaptor protein, STAP-2 is controlled by E3 ubiquitin ligase Cbl. Biochem. Biophys. Res. Commun., 384, 187-192 (2009).

42) Karin M. The beginning of the end: I $\kappa \mathrm{B}$ kinase (IKK) and NF- $\kappa \mathrm{B}$ activation. J. Biol. Chem., 274, 27339-27342 (1999).

43) Gould HJ, Sutton BJ. IgE in allergy and asthma today. Nat. Rev. Immunol., 8, 205-217 (2008).

44) Turner H, Kinet JP. Signalling through the high-affinity IgE receptor Fc epsilonRI. Nature, 402, 24-30 (1999).

45) Li W, Deanin GG, Margolis B, Schlessinger J, Oliver JM. Fc ep- silon R1-mediated tyrosine phosphorylation of multiple proteins, including phospholipase $\mathrm{C}$ gamma 1 and the receptor beta gamma 2 complex, in RBL-2H3 rat basophilic leukemia cells. Mol. Cell. Biol., 12, 3176-3182 (1992).

46) Rivera VM, Brugge JS. Clustering of Syk is sufficient to induce tyrosine phosphorylation and release of allergic mediators from rat basophilic leukemia cells. Mol. Cell. Biol., 15, 1582-1590 (1995).

47) Suzuki K, Verma IM. Phosphorylation of SNAP-23 by IkappaB kinase 2 regulates mast cell degranulation. Cell, 134, 485-495 (2008). 48) Leung DY, Sampson HA, Yunginger JW, Burks AW Jr, Schneider LC, Wortel CH, Davis FM, Hyun JD, Shanahan WR Jr. Effect of anti-IgE therapy in patients with peanut allergy. N. Engl. J. Med., 348, 986-993 (2003).

49) Sampson HA, Muñoz-Furlong A, Campbell RL, et al. Second symposium on the definition and management of anaphylaxis: summary report-Second National Institute of Allergy and Infectious Disease/ Food Allergy and Anaphylaxis Network symposium. J. Allergy Clin. Immunol., 117, 391-397 (2006).

50) Fujita N, Oritani K, Ichii M, Yokota T, Saitoh N, Okuzaki D, Sekine Y, Kon S, Muromoto R, Saitoh K, Yoshimura A, Matsuda T, Kanakura Y. Signal-Transducing Adaptor Protein-2 regulates macrophage migration into inflammatory sites during dextran sodium sulfate-induced colitis. Eur. J. Immunol., 44, 1791-1801 (2014).

51) Ichii M, Oritani K, Toda J, Saito H, Shi H, Shibayama H, Motooka D, Kitai Y, Muromoto R, Kashiwakura JI, Saitoh K, Okuzaki D, Matsuda T, Kanakura Y. Signal-transducing adaptor protein-2 delays recovery of B lineage lymphocytes during hematopoietic stress. Haematologica, 106, 424-436 (2021).

52) Saito H, Ichii M, Toda J, Kitai Y, Muromoto R, Kashiwakura JI, Saitoh K, Tanimura A, Yokota T, Shibayama H, Matsuda T, Oritani K, Kanakura Y, Hosen N. Graft-versus-host disease develops in mice transplanted with lymphocyte-depleted bone marrow cells from signal-transducing adaptor protein-2 transgenic mice. Biochem. Biophys. Res. Commun., 537, 118-124 (2021). 